\title{
AVALIAÇÃO DE RESÍDUO DO HERBICIDA IMAZETHAPYR E DA INTERFERÊNCIA DE PLANTAS DANINHAS NA CULTURA DA ALFAFA ${ }^{1}$
}

\author{
JULIANA Z. PAGOTTO ${ }^{2}$, RICARDO A. REIS ${ }^{3}$ e JULIO C. DURIGAN ${ }^{4}$
}

\section{RESUMO}

Foram conduzidos dois experimentos de campo em área experimental do Departamento de Nutrição Animal e Pastagens da Faculdade de Ciências Agrárias e Veterinárias (UNESP), Campus de Jaboticabal, com o objetivo de observar resíduos do herbicida imazethapyr na forragem da alfafa e analisar a interferência de plantas daninhas monocotiledôneas e dicotiledôneas.

No primeiro experimento, o herbicida foi aplicado nas doses de 0,5 e 1,0 1 do p.c./ha, nos estádios de desenvolvimento: início de brotação das gemas basais, estádio vegetativo, ou seja, antes da cobertura total do solo e início do florescimento da alfafa.. Foi observado que o herbicida não deixou resíduo nas plantas da alfafa, podendo estas serem consumidas pelos animais, logo após seu tratamento. No segundo experimento, foi estabelecido com base no manejo de cortes da área experimental e na presença de plantas daninhas, quatro tratamentos: 1)corte no verão de 1996, sem a presença de invasoras, 2)corte no inverno de 1996, sem a presença de invasoras, 3)corte no verão de 1997, com predominância de espécies monocotiledôneas, 4)corte no verão de 1997, com predominância de espécies dicotiledôneas.

A presença de plantas daninhas reduziu a produção de matéria seca da alfafa. Quanto aos valores de parede celular, observou menores de Hem $(5,7)$ e Lig $(5,1)$ e maior de PB $(26,1 \%)$ nas plantas colhidas no inverno, devido à maior proporção de folhas.

Palavras chave: mendicago sativa $\mathrm{L}$, competição.

\section{ABSTRACT \\ Effect of Imazethapyr residue and weed interference in alfalfa}

Two field experiments were carried out in an experimental area of the FCAV/UNESP Jaboticabal/SP, Brazil, aiming to observe imazethapyr residues in the forage of the alfalfa and to analyze the interference of monocotyledons and dicotyledons weeds. In the first experiment, the herbicide was applied at rates of 0,5 and 1,0 $l$ of p.c./ha on the development stadium: bud sprouting, vegetative stadium, that is, before the total covering of the soil and beginning of the flowering of the alfalfa.. Since no herbicide residues were found in the alfalfa plants, they can be consumed by the animals, right after its treatment. In the second experiment, four treatments were established concerning the handling of courts of the experimental area and in the presence of weeds: 1) cut in the summer of 1996, without the weed presence, 2) cut in the winter of 1996, without the weed presence, 3) cut in the summer of 1997, with the presence of monocotyledons, 4) cut in the summer of 1997 ,

\footnotetext{
${ }^{1}$ Recebido para publicação em 15/06/97 e na forma revisada em 23/11/97.

${ }^{2}$ Eng $^{\circ} \mathrm{Agr}^{\circ}$, Dept $^{\circ}$ de Defesa Fitossanitária, FCAVJ/UNESP, CEP 14870-000, Jaboticabal/SP.

${ }^{3}$ Eng $^{\circ}$ Agr $^{\circ}$, Dept ${ }^{\circ}$ de Defesa Fitossanitária, FCAVJ/UNESP, CEP 14870-000, Jaboticabal/SP.

${ }^{4}$ Prof. Adjunto, Dept ${ }^{\circ}$ de Defesa Fitossanitária, FCAVJ/UNESP, CEP 14870-000, Jaboticabal/SP.
} 
with the presence of dicotyledons. The presence of weeds reduced the production of dry matter of the alfalfa. Concerning the values of the cellular wall, lower values of Hem $(5,7)$ and $\operatorname{Lig}(5,1)$ and higher value of PB $(26,1 \%)$ were observed in the

\section{INTRODUÇÃO}

A exploração pecuária intensiva requer a utilização de forragem de boa qualidade nutricional durante todo o ano, a fim de atender às exigências dos animais de alta produção. Dentre as plantas forrageiras cultivadas no Brasil, a alfafa (Medicago sativa L.) apresenta essas qualidades além de grande variabilidade genética, o que possibilita sua adaptabilidade a regiões com diferentes condições edafoclimáticas. (Nuernberg et al., 1990 e Vilela, 1992). Dentre os principais fatores limitantes a expansão do cultivo da alfafa em regiões de clima tropical estão os relacionados com a fertilidade do solo, manejo de plantas daninhas e da cultura.(Honda \& Honda, 1990).

É importante considerar que, nas condições edafoclimáticas do Brasil Central, ocorre intensa incidência de plantas daninhas principalmente no verão que competem com a cultura da alfafa, .sendo o controle destas plantas fundamental, pois, além de competirem com os cultivos, servem de hospedeiras para pragas e doenças, podendo ainda, dificultar a colheita mecânica, causar perdas e afetar a qualidade do produto. Em média, a interferência das plantas daninhas é responsável por 30 a $40 \%$ na redução da produção agrícola dos países tropicais (Vilela, 1992). A convivência com estas plantas leva ainda à redução na produção de matéria seca (PMS) da alfafa, devido a efeitos alelopáticos e pela competição por água, luz, nutrientes e espaço físico, acarretando diminuição na qualidade da forragem e das sementes produzidas (Peters \& Linscott, 1988; Oliveira et al.,1997).

Devido ao espaçamento recomendado para a cultura, o controle mecânico das plantas daninhas é muito difícil e o manual é muito lento, sendo viável apenas em pequenas áreas. A utilização de herbicidas é uma alternativa para plants picked in the winter, due to the largest proportion of leaves.

Key words: mendicago sativa L., competition.

áreas maiores. Entretanto, existem poucas informações seguras, principalmente de herbicidas com ação sobre plantas daninhas de folhas largas e seletivos para as plantas de alfafa, na fase inicial de desenvolvimento, período em que a cultura é mais sensível à interferência das plantas daninhas (Fontes et al., 1994; Mello et al., 1996).

Antes da utilização dos herbicidas seletivos, as plantas daninhas da alfafa eram controladas principalmente através do manejo e práticas culturais antes e após a implantação da cultura. Herbicidas seletivos começaram a ser usados em meados de 1940, mas com pouca utilização na alfafa, uma vez que eram caros, não inteiramente eficazes, e com altos riscos de injúrias na planta (Peters \& Linscott, 1988).

De modo geral, recomendam-se os graminicidas utilizados na cultura da soja, pois esta se assemelha à alfafa por serem duas leguminosas, sendo que a nível de campo, a alfafa tem tido maior resistência aos herbicidas quando comparada à soja (Honda \& Honda, 1990).

Um dos problemas para o estabelecimento das plantas de alfafa no campo, tem sido a fitoxicidade dos herbicidas aplicados em pré ou em pós-emergência (Hasting \& Kust, 1970; Kust, 1969; Oliveira et al.,1997), mas foi observado que imazethapyr, aplicado nas doses de 0,1 e 0,2 $\mathrm{kg} / \mathrm{ha}$, não causou efeito fitotóxico na alfafa (Malik et al., 1993). Da mesma forma, Wilson, (1994), constatou que o imazethapyr não reduziu a produção de matéria seca da alfafa no primeiro corte e diminuiu acentuadamente a biomassa das plantas daninhas. Além da eficiência no controle de plantas daninhas, é interessante considerar que o herbicida utilizado não deve resultar em acúmulo de resíduos que possam interferir no valor nutritivo da forragem.

Assim, o objetivo deste trabalho foi obter informações sobre a possibilidade de aparecimento 
de resíduo do herbicida imazethapyr na forragem da alfafa, após aplicação em três estádios de desenvolvimento e avaliar a intensidade de interferência das plantas daninhas monocotiledôneas e dicotiledôneas sobre a produção de matéria seca e composição química das plantas de alfafa.

\section{MATERIAIS E MÉTODOS}

Foram instalados dois experimentos na UNESP-Jaboticabal em Latossolo Roxo de textura argilosa, com topografia medianamente declivosa. A semeadura da alfafa (Medicago sativa L.) cultivar Crioula foi realizada em 19/06/95, observando o espaçamento de $0,30 \mathrm{~m}$, com distribuição de aproximadamente 60 plantas por metro linear. As sementes foram inoculadas com a bactéria aeróbica simbiótica (Rhizobium melilloti), que foram umedecidas e misturadas com o inoculante, secadas à sombra e semeadas em seguida. A quantidade usada de inoculante foi de $10 \mathrm{~g}$ por $\mathrm{kg}$ de semente ou $1 \%$.

Em maio de 1995 fez-se aração, com arado de aiveca a $30 \mathrm{~cm}$ de profundidade e posteriormente a aplicação de $1870 \mathrm{~kg}$ de superfosfato simples por hectare, equivalente a $130 \mathrm{~kg}$ de $\mathrm{P}_{2} \mathrm{O}_{5}$ por hectare. Em seguida aplicou-se trifluralin (Treflan) em pré plantio no dia 25/05/95, na dose de $801,0 \mathrm{~g}$ i.a./ha $(1,81$ do produto comercial por hectare) e consumo de 3001 de calda por hectare. Este herbicida foi incorporado ao solo com grade, objetivando-se a proteção do mesmo com relação à fotodecomposição e volatilização. $\mathrm{O}$ espectro de controle deste herbicida é composto predominantemente por gramíneas.

No dia 02/06/95 aplicou-se $1300 \mathrm{~kg}$ de Termofosfato-Yoorin Master-1 por hectare e $15 \mathrm{t}$ de composto orgânico Provaso PV1 por hectare, que também foram incorporados com grade niveladora. Em 10/06/95 fez-se uso de arado escarificador, a $40 \mathrm{~cm}$ de profundidade aproximadamente, e posteriormente trabalhou-se com enxada rotativa a $10 \mathrm{~cm}$ de profundidade, em duas passadas.
Após a adubação fez-se outra análise do solo, para verificar a condição de fertilidade atingida, detectando os seguintes valores: $\mathrm{pH}$ em $\mathrm{CaCl}_{2}=6,3 ; \mathrm{MO}=2,4 \% ; \mathrm{P}_{\text {resina }}=48 \mu \mathrm{g} / \mathrm{cm}^{3}$; $\mathrm{K}=0,42^{*} ; \mathrm{Ca}=5,6^{*} ; \mathrm{Mg}=3,0^{*} ; \mathrm{H}+\mathrm{Al}=1,9^{*}$; $\mathrm{Al}=0,0^{*} ; \mathrm{CTC}$ (capacidade de troca catônica $)=$ $10,92 *\left(*\right.$ meq $/ 100 \mathrm{~cm}^{3}$ de TFSA ) e saturação em bases (V\%) de $82,6 \%$.

A área foi irrigada por sistema de aspersão convencional para evitar deficiência hídrica.

\section{Experimento 1}

$\mathrm{O}$ experimento 1, desenvolvido para avaliação da quantidade de resíduo do herbicida Imazethapyr na cultura da alfafa, foi iniciado em 08/10/96, data referente ao corte de uniformização.

O herbicida foi aplicado nas doses do produto comercial de 0,5 e 1,0 1/ha, com o pulverizador costal manual quando as plantas de alfafa atingiram os seguintes estádios de desenvolvimento: início de brotação das gemas basais com 7 dias após o corte, estádio vegetativo, ou seja, antes da cobertura total do solo com 14 dias após o corte e início do florescimento da alfafa, com 23 dias após o corte, observando as condições climáticas, conforme dados da tabela Tabela 1.

Para realização dos cortes, observou-se o critério de $10 \%$ a $20 \%$ de florescimento, sendo efetuados a $10 \mathrm{~cm}$ do nível do solo (Honda \& Honda, 1990). Após cada corte foi feita adubação de cobertura com cloreto de potássio, sendo que a dose anual de $600 \mathrm{~kg}$ de $\mathrm{K}_{2} \mathrm{O} / \mathrm{ha}$ foi subdividida em oito aplicações, considerando-se, que em média, tem-se oito cortes por ano. $\mathrm{O}$ adubo foi aplicado por via líquida, dissolvendo-se a dose equivalente a cada parcela em um regador com água.

O corte para a coleta das amostras foi feito em 06/11/96 e após este, foi feita a pesagem da forragem verde de cada parcela com área útil de 4 metros quadrados, no campo, retirando-se uma amostra de cada, que foi acondicionada em saco de papel e armazenadas em gelo seco para garantir a conservação durante o transporte, para análise do 
resíduo do herbicida. Este procedimento também foi adotado para o feno seco ao sol.

As amostras foram armazenadas no laboratório da Cyanamid Química do Brasil Ltda, à temperatura de menos $15^{\circ} \mathrm{C} \mathrm{e} \mathrm{em} \mathrm{seguidas} \mathrm{foram}$ picadas com gelo seco, homogeneizadas e armazenadas sob refrigeração até início da análise.

As análises do resíduo do herbicida imazethapyr (CL 263,499) foram efetuadas de acordo com as técnicas descritas por American
Cyanamid Company Agricultural Research Division Chemical Development (1991).

Os resíduos foram avaliados em cromatografia líquida, usando um instrumento equipado com detector de nitrogênio. Os resultados foram calculados através dos picos encontrados para o produto CL 263,499 comparado com os padrões. A sensibilidade do método foi de 0,05 ppm para cada composto.

TABELA 1. Condições climáticas durante as aplicações do herbicida imazethapyr.

\begin{tabular}{ccccccc}
\hline $\begin{array}{c}\text { Data } \\
\text { Hora }\end{array}$ & $\begin{array}{c}\text { Estádio da } \\
\text { Cultura }\end{array}$ & $\begin{array}{c}\text { Temp. } \\
\text { Ambiente }\end{array}$ & $\begin{array}{c}\text { Ur. } \\
\text { do Ar }\end{array}$ & $\begin{array}{c}\text { Temp. } \\
\text { do Solo } \\
(5 \mathrm{~cm} \text { de } \\
\text { prof. })\end{array}$ & $\begin{array}{c}\text { Velocidade } \\
\text { do Vento }\end{array}$ & Nebulosidade \\
\hline $\begin{array}{c}15 / 10 / 96 \\
8: 30 \mathrm{hs}\end{array}$ & $\begin{array}{c}\text { Início da } \\
\text { brotação das } \\
\text { gemas basais }\end{array}$ & $21^{\circ} \mathrm{C}$ & $82 \%$ & $20^{\circ} \mathrm{C}$ & $\begin{array}{c}<2 \mathrm{~km} / \mathrm{h} \\
\text { Sem perdas } \\
\text { por deriva }\end{array}$ & $0 \%$ \\
\hline $\begin{array}{c}\text { Antes da } \\
\text { 9:10/96 }\end{array}$ & $\begin{array}{c}\text { Ans } \\
\text { cobertura total } \\
\text { do solo }\end{array}$ & $25^{\circ} \mathrm{C}$ & $68 \%$ & $21^{\circ} \mathrm{C}$ & $\begin{array}{c}<2 \mathrm{~km} / \mathrm{h} \\
\text { Sem perdas } \\
\text { por deriva }\end{array}$ & $50 \%$ \\
\hline $01 / 11 / 96$ & $\begin{array}{c}\text { Início do } \\
\text { florescimento }\end{array}$ & $26^{\circ} \mathrm{C}$ & $84 \%$ & $25,5^{\circ} \mathrm{C}$ & $\begin{array}{c}<2 \mathrm{~km} / \mathrm{h} \\
\text { Sem perdas } \\
\text { por deriva }\end{array}$ & $90 \%$ \\
\hline 15:20hs & & & & & \\
\hline
\end{tabular}

\section{Experimento 2}

Com base no manejo de cortes da área experimental, foram estabelecidos quatro tratamentos para se avaliar os efeitos das plantas daninhas sobre a produção de matéria seca e composição química da alfafa: 1)corte no verão de 1996, sem a presença de invasoras, 2)corte no inverno de 1996, sem a presença de invasoras, 3)corte no verão de 1997, com predominância de espécies monocotiledôneas, 4)corte no verão de 1997, com predominância de espécies dicotiledôneas. Estes tratamentos foram estabelecidos na área experimental uma vez que Mello (1996) conduziu um estudo para verificar os efeitos fitotóxicos de diferentes herbicidas na cultura da alfafa, mantendo a área sem a presença de plantas daninhas através da capina manual (verão e inverno de 1996).
Desta forma, estabeleceu-se os tratamentos deste experimento 2 com o propósito de se verificar os efeitos desse manejo (sem competição de plantas daninhas) sobre a capacidade de competição da alfafa com as invasoras no verão de 1997.

Os dados obtidos no experimento foram analisados segundo o delineamento em blocos casualizados e com oito repetições de campo.

O corte de verão de 1996, foi realizado em 13/03/96, quando na referida área realizou-se a capina manual após todos os cortes realizados anteriormente. Após o corte foi feita a pesagem da forragem verde de cada parcela com área útil de quatro metros quadrados, no campo. A seguir retirou-se uma amostra de cada, que foi acondicionada em saco de papel, pesada verde, e posteriormente secada em estufa a $65^{\circ} \mathrm{C}$ até atingir peso constante, determinando-se o conteúdo de matéria seca (Silva, 1990). Em seguida as 
amostras foram moídas, para posteriormente determinar os conteúdos de proteína bruta, fibra em detergente neutro (FDN), fibra em detergente ácido (FDA), hemicelulose, celulose e lignina, segundo Silva (1990).

No período de inverno no dia $05 / 07 / 96$, foi realizado um corte, quando determinou-se a produção de matéria seca e a composição química das plantas de alfafa, segundo os métodos descritos anteriormente. Durante o período de inverno, o número de plantas invasoras reduziu acentuadamente devido ao clima e capina realizada.

No período de verão no dia (06/02/97), foi realizado um corte para determinação da produção de matéria seca, bem como a incidência de plantas invasoras. A produção de matéria seca e a avaliação da composição química da alfafa foram determinados, colhendo as parcelas com 4,0 metros quadrados de área útil.

$\mathrm{Na}$ área experimental, no período de verão de 1997, foram observados dois tipos básicos de infestação, uma com predominância de espécies monocotiledôneas, e outra com dicotiledôneas (Tabela 2).

A incidência de plantas invasoras foi determinada mediante o uso de um retângulo com $1,0 \times 0,6$ metros, lançado ao acaso nas parcelas. As plantas contidas no retângulo foram cortadas, pesadas e encaminhadas ao laboratório onde se procedeu a separação da alfafa e das invasoras. Após a separação as amostras verdes da alfafa eram pesadas, colocadas em estufas a $65^{\circ} \mathrm{C}$, a fim de se determinar o conteúdo de MS, permitindo o cálculo dos teores de MS. Em seguida as amostras foram moídas para, posteriormente, determinar os conteúdos de proteína bruta, FDN, FDA, hemicelulose, celulose e lignina.

TABELA 2. Espécies de plantas daninhas Monocotiledôneas e Dicotiledôneas identificadas na cultura da alfafa no ano de 1996 (controladas com capina) e no corte de verão (06/02/97).

\begin{tabular}{cc}
\hline Nome científico & Plantas daninhas \\
\hline Digitaria insulares (L.) Mea ex Ekman Brachiaria & Capim-amargoso \\
plantaginea (Link) Hitch Eleusine indica (L.) Gaertn. & Capim-marmelada \\
Commelina nudiflora L. & Capim-pé-de-galinha \\
& trapoeraba \\
\hline Alternanthera ficoidea (L.) R. BR. & apaga-fogo \\
Amaranthus deflexus L. & caruru \\
Bidens pilosa L. & picão-preto \\
Parthenium hysterophorus L. & losna-branca \\
\hline
\end{tabular}

\section{RESULTADOS E DISCUSSÃO}

\section{Experimento 1}

Constatou-se que o imazethapyr nas duas doses aplicadas em diferentes estádios de desenvolvimento das plantas de alfafa, não resultaram em acúmulo de resíduo na forragem verde da alfafa, apresentando em todos os tratamentos teores $<0,05 \mathrm{ppm}$, que foi a concentração mínima detectada pelo método de análise empregado. Desta forma, as plantas de alfafa, poderão ser consumidas pelos animais com 36, 14 e 05 dias após a aplicação com o herbicida imazethapyr. Estes dados são muito importantes devido a falta de informações sobre resíduo de herbicidas em culturas (principalmente forrageiras).

\section{Experimento 2}

A análise dos dados da Figura 1, mostra que houve maior acúmulo de matéria seca na alfafa, durante o período de verão e inverno sem a interferência de plantas invasoras, e menor acúmulo durante o verão quando a alfafa foi cultivada com interferência de plantas invasoras monocotiledôneas e dicotiledôneas. Isto se deve à 
competição que ocorre entre as plantas daninhas e a alfafa por luz, nutrientes, espaço físico e possíveis efeitos alelopáticos. Observou-se também que a produção de MS no verão (sem a interferência de plantas daninhas), foi superior ao observado no inverno, sendo tal fato relacionado as condições de temperatura e luminosidade (Tabela 3).

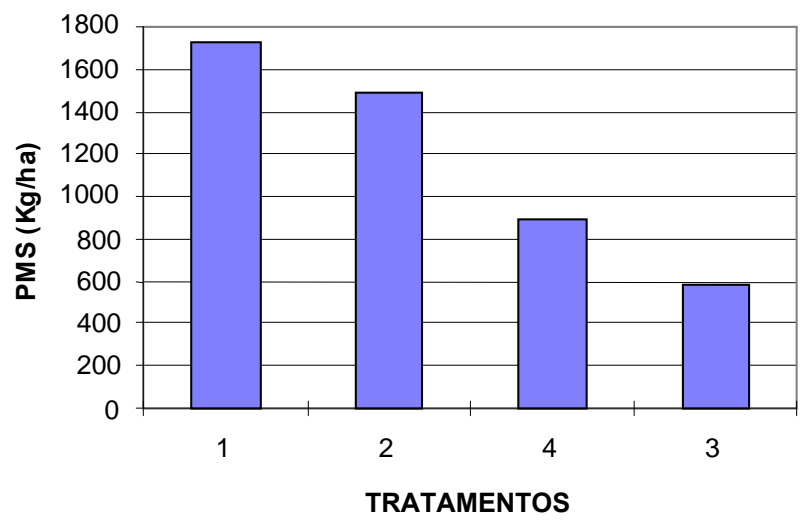

\section{LEGENDA:}

1-Plantas de alfafa cultivadas no verão de 1996

2-Plantas de alfafa cultivadas no inverno de 1996

3-Plantas de alfafa cultivadas no verão de 1997 com interferência de plantas daninhas Monocotiledôneas

4-Plantas de alfafa cultivadas no verão de 1997 com interferência de plantas daninhas Dicotiledôneas

FIGURA 1. Média das produções de matéria seca da alfafa colhida no verão (1996) e inverno (1996) sem a interferência de invasoras, e no verão (1997) com a interferência de plantas invasoras Monocotiledôneas e Dicotiledôneas.

TABELA 3. Produção de Matéria seca (PMS), teores (\% MS) de constituintes da parede celular e de proteína bruta da alfafa colhida em diferentes épocas e submetidas a diferentes manejos.

\begin{tabular}{cccccccc}
\hline Tratamentos & $\begin{array}{c}\text { PMS } \\
\text { (kg/ha) }\end{array}$ & FDN & FDA & HEM. & CEL. & LIG. & PB \\
& & & & & & \\
\hline Verão - SI & $1728,6 \mathrm{~A}$ & $39,4 \mathrm{~A}$ & $31,4 \mathrm{~A}$ & $7,9 \mathrm{~A}$ & $23,1 \mathrm{BC}$ & $8,2 \mathrm{~A}$ & $22,9 \mathrm{~B}$ \\
Inverno - SI & $1399,2 \mathrm{~B}$ & $32,9 \mathrm{~A}$ & $27,1 \mathrm{~A}$ & $5,7 \mathrm{~B}$ & $21,9 \mathrm{C}$ & $5,1 \mathrm{~B}$ & $26,1 \mathrm{~A}$ \\
Verão - IFM & $128,0 \mathrm{C}$ & $38,1 \mathrm{~A}$ & $30,5 \mathrm{~A}$ & $7,5 \mathrm{~A}$ & $24,4 \mathrm{AB}$ & $6,1 \mathrm{~B}$ & $21,1 \mathrm{C}$ \\
Verão - IFD & $184,6 \mathrm{C}$ & $39,1 \mathrm{~A}$ & $31,4 \mathrm{~A}$ & $7,6 \mathrm{~A}$ & $25,3 \mathrm{~A}$ & $6,0 \mathrm{~B}$ & $22,2 \mathrm{BC}$ \\
C.V. & 11,78 & 6,85 & 6,09 & 15,33 & 6,54 & 14,95 & 4,50 \\
\hline
\end{tabular}

Médias seguidas de mesma letra nas colunas, não diferem $(\mathrm{P}>0,05)$ pelo teste de TUKEY.

SI- sem interferência de invasoras

IFM- com interferência de invasoras Monocotiledôneas

IFD- com interferência de invasoras Dicotiledôneas

FDN= Fibra em Detergente Neutro; FDA= Fibra em Detergente Ácido; HEM.= Hemicelulose; CEL.= Celulose; LIG.= Lignina. 
As espécies monocotiledôneas observadas são plantas $\mathrm{C}_{4}$, que apresentam intenso crescimento no verão e acarretam com isto, competição com as plantas de alfafa pelos fatores ambientais.

É importante considerar que as espécies dicotiledôneas e monocotiledôneas observadas neste estudo são muito mais adaptadas às condições edafoclimáticas de Jaboticabal, comparado com a alfafa (Tabela 2).

Na Tabela 3 estão relacionados os dados obtidos de produção de matéria seca, teores de constituintes da parede celular e de proteína bruta da alfafa colhida em diferentes épocas e submetida a diferentes manejos.

A incidência de plantas invasoras com predominância de monocotiledôneas, reduziu a produção de matéria seca da alfafa em $92,6 \%$ e com predominância de dicotiledôneas reduziu em $89,4 \%$, comparando com a produção de matéria seca da alfafa cultivada no verão sem a interferência de plantas invasoras.

Comparando os valores obtidos de produção de MS da alfafa cultivada no inverno com aqueles obtidos no verão com a interferência de plantas daninhas, nota-se uma redução de 90,9\% na produção de matéria seca da alfafa cultivada com plantas invasoras monocotiledôneas e uma redução de $86,81 \%$ sobre a interferência de invasoras dicotiledôneas concordando assim com dados de Rassini e Freitas (1995), que relatam que a produção de MS da alfafa foi reduzida pela competição de uma comunidade vegetal infestante em 60\%. Dawson e Rincker, (1982) constataram que a alfafa, desenvolvendo em competição com uma densa população ( 40 plantas/ $\mathrm{m}^{2}$ ) de espécies mistas de infestantes anuais, teve sua produção reduzida em 95\%. Quando ocorreu competição com densa população de plantas de folhas largas (55 plantas $\left./ \mathrm{m}^{2}\right)$, baixa população $\left(4\right.$ plantas $\left./ \mathrm{m}^{2}\right)$ e população alta de Echinochloa crusgalli (75 colmos $/ \mathrm{m}^{2}$ ) a produção foi reduzida de 90,6 e $80 \%$, respectivamente.

Quanto aos valores observados de constituintes da parede celular (FDN, FDA,
HEM), nota-se que houve diferença significativa somente entre o tratamento em que a alfafa foi cultivada no inverno comparado com o crescimento de verão.

Estes dados estão relacionados aos fatores de clima e temperatura. No verão, a alfafa apresenta um crescimento elevado acarretando maior acúmulo da fração caule e de parede celular e diminuição nos teores de proteína bruta.

Em relação aos valores de FDA, observase redução de $12,9 \%$ na alfafa cultivada no período de inverno enquanto que para os valores de FDN, observa-se redução de $15,2 \%$. Para os valores de hemicelulose, nota-se redução de $25 \%$ nas plantas cultivadas no inverno.

Os valores de celulose, também foram reduzidos $(\mathrm{P}<0,05)$ quando a alfafa foi cultivada no período de inverno, acarretando menor acúmulo de parede celular.

Dados referentes aos valores de lignina em alfafa, são escassos na literatura nacional. Em relação aos valores observados na Tabela 3 , notase que a alfafa apresenta crescimento elevado no verão quando está sem a interferência de plantas daninhas, acarretando maior acúmulo de massa e de lignina. É importante considerar que no período de verão, observou-se que as plantas apresentavam caules mais desenvolvidos e mais lignificados, resultando em menores porcentagens de proteína bruta, enquanto que no inverno, apresentavam caules mais tenros, folíolos maiores e em maiores proporções.

Quanto aos valores de proteína bruta, observa-se que no inverno a alfafa apresenta maior teor deste componente, sendo de qualidade elevada e apresentando características nutricionais adequadas para o consumo animal.

A alfafa combina as virtudes de alta produção de matéria seca por área e alto teor de proteína bruta. De acordo com os dados da Tabela 3 , o teor de proteína bruta da alfafa cultivada no inverno està em torno de $26,1 \%$ e da alfafa cultivada no verão, $22,1 \%$. Os dados observados estão de acordo com os constatados por Carvalho e Vilela (1994). 


\section{LITERATURA CITADA}

American Cyanamid Company Agricultural Research Division Chemical Development. Recommended Method of Analysis. American Cyanamid Company. Princeton, New Jersey. 1991. p. 4-43.

DAWSON, J.H., RINCHER, C.M. Weeds in new seedlings of alfalfa (Medicago sativa) for seed production: competition and control. Weed Sci., v. 30, p. 20-25, 1982.

FONTES, P.C.R., VILELA, D., MARTINS, C.M. Estabelecimento da cultura da alfafa. In: Cultura da alfafa: estabelecimento, fenação, custo de produção e construção de um secador estático. CARVALHO, L. de A., VILELA, D. Coronel Pacheco: EMBRAPA, 1994. p. 1-11.

HASTING, R.E., KUST, C.A. Control of yellow rocket and white elover cockle in established alfalfa. Weed Sci., v. 18, n. 2, p. 239-333. 1970.

HONDA, C.S., HONDA, A.M. Cultura da alfafa. Marília: Artes Gráficas Ltda, 1990. 245 p.

KUST, C.A. Selective control of hoar alyssum in alfafa. Weed Sci., v. 17, n. 1. p. 99-101. 1969.

MALIK, N., BOWES, G.G., WADDINGTON, J. Residual herbicides for weed control in established alfalfa (Medicago sativa L.) grown for seed. Weed technol., v. 7, n. 3, p. 483-490. 1993.

MELLO, de G. Avaliação da seletividade de herbicidas aplicados em pós-emergência na cultura da alfafa (Medicago sativa L.). Jaboticabal: $\quad$ FCAVJ/UNESP, 1996. (Trabalho de Graduação).

NUERNBERG, N.J., MILAN, P.A., SILVEIRA, C.A.M. Manual de produção de alfafa. Florianópolis: EMPASC, 1990. 102 p.

OLIVEIRA, P.P.A., SANTOS, P.M., CORSI, M., FILHO, R.V., DIAZ, M.D.P. Estudos dos efeitos de fitotoxicidade de provenientes do uso de herbicidas no estabelecimento e em culturas estabelecidas de alfafa (Medicago sativa L.). Rev. Soc. Bras. Zoot., v. 26 , n. 1, p. 19-26, 1997.

PETERS, E.J., LINSCOTT, D.L. Weeds and weed control. In: Alfalfa and alfalfa improvement. HANSON, A.A. BARNES, D.K., HILL, R.R. (Eds.). Madison: ASA, CSSA, SSSA, p. 705-735. 1988.

RASSINI, J.B., FREITAS, A.R. Efeitos da interferência de plantas daninhas no rendimento da cultura da alfafa (Medicago sativa L.). Rev. Soc. Bras. Zoot., v. 24 , n. 4, p. 502-9, 1995.

SILVA, D.J. Análise de alimentos. Métodos químicos e biológicos. 2. ed. Universidade Federal de Viçosa. Imprensa Universitária. 1990. $165 \mathrm{p}$.

VILELA, D. Potencialidade da alfafa na região Sudeste do Brasil. Inf. Agropec., v. 16, n. 175 , p. 50-3, 1992.

WILSON, R.G. Effect of imazethapyr on legumes and the effects of legumes on weeds. Weed Techonol., v. 8, n. 3, p. 536-640. 1994. 